\title{
A Systematic Review of Second Language Learning with Mobile Technologies
}

\author{
https://doi.org/10.3991/ijet.v13i02.8094 \\ Veronica Persson, Jalal Nouri $\left.{ }^{\square}\right)$ \\ Stockholm University, Sweden \\ jalaledsv.su.se
}

\begin{abstract}
This study provides a systematic literature review of the research done in mobile assisted second language learning (MASLL) published since 2010. Starting from 1424 sources, 54 articles were selected using predefined selection criteria. The documents were analyzed and coded using the categories: educational form and level, study design, location, context, role of technology, pedagogical practice and learning impact. That information allowed an identification of major educational outcomes related to the integration of mobile devices into second language learning. In addition, the study contributes with a set of identified research gaps and recommendations for future research.
\end{abstract}

Keywords—-second language learning; mobile learning; mobile technologies; MASLL

\section{Introduction}

Mobile technologies have been incorporated in almost every aspect of our daily live offering mobility, portability, and usability. Users began to prefer smaller mobile devices with touch screen interfaces over traditional PC, having implications for many sectors of the society [1]. Mobile devices nowadays can be considered as allpurpose computing devices that can help to perform everyday tasks providing services in different fields such as banking, e-commerce, and education [2]. The use of mobile devices has not been limited by age, and therefore the number of young users have also increased. Thus, mobile devices have a significant role in daily life, yet both as a distraction and as an educational tool [3][4].

In the educational field, the use of mobile technologies has become a hot trend as tablets and smartphones can offer several learning opportunities [3][5]. Compared with Pcs and laptops, mobile devices such as smartphones and tablet PCs have several advantages. They are lighter, smaller and it is easy to interact with them on the move [6]. The touch screen also permits the student to interact directly with the interface thus creating new pedagogical approaches that allow the teacher to act as a facilitator and enhances student participation [7].

Several investigations have tried to identify the advantages that the use of mobile technologies brings to education, such as increased opportunities for communication, collaborative interaction, independent learning, and production of digital material 
[7][8]. Other studies have tried to identify the impact of mobile technologies on the acquisition of a second language. According to [9], mobile devices offers attractive alternatives to learning by the use of different kind of applications, for instance, game-based learning applications. Learners can use different applications in informal contexts that can help to increase vocabulary, improve reading and listening comprehension, as well as helping with translations, spelling and grammar revisions.

It is against such a background mobile-assisted language learning (MALL) has become a relevant area within the field of mobile learning [10] [11]. However, there is an absence of systematic reviews that shed light on studies investigating the use of mobile technology for learning a second language. Therefore, the aim of this paper is to report on a systematic review of different projects that investigate mobile technologies as a tool to support the learning of a second language, examining the various trends of the research done during the last years.

\section{$1.1 \quad$ Research questions}

The present review is based on the following general research question with associated sub-questions: Which are the major trends in studies about the use of mobile technologies as a tool for second language learning (SLL)?

- Which are the major methodologies and learning outcomes identified?

- What role do mobile technologies play in research on second language learning?

- What kind of pedagogical second-language learning practices are supported with mobile technologies?

- In what context are mobile technologies utilized for second-language learning?

- Which are the major similarities and contradictions of conducted studies?

- Which are the gaps not addressed in these studies?

\section{Background}

\subsection{Mobile technologies}

Mobile technologies have been incorporated in almost every aspect of our daily live offering mobility, portability and lower prices than PCs. The first commercial device available in the market was the Apple Newton message pad in 1993 followed by the Palm Pilot in 1996 The Palm Pilot offered the users several advantages compared with the Newton, such as word processing, database, and spreadsheet programs, gaining popularity among business professionals and educators. However, it was until the release the iPhone in 2007 when the popularity of mobile devices increased not only among adults but also between a younger population.

Apple continued releasing mobile devices such as the iPod touch, the first nonphone PDA in 2007, which marked the beginning of the handheld devices in the education market. It is until 2010 that the first iPad is launched in the marked. The iPad 
included the functionality for video and audio recorder of the iPod but adding the eBook reader functionality. The evolution of mobile devices is summarized in Table1.

Table 1. Mobile devices timeline [12]

\begin{tabular}{|l|l|}
\hline Year & \multicolumn{1}{|c|}{ Device } \\
\hline 1993 & Newton Message Pad - First PDA on the market \\
\hline 1996 & Palm Computing - First commercially successful PDA \\
\hline 2001 & Microsoft tablet PC - First tablet on the market \\
\hline 2001 & Apple iPod - First commercially successful MP3player \\
\hline 2007 & Apple iPhone - First smartphone from Apple - iOS released \\
\hline 2007 & Apple iPod touch - First non-phone PDA from Apple \\
\hline 2007 & Amazon Kindle - First commercially successful eBook reader \\
\hline 2008 & Google Android OS - First serious competitor to Apple iOS \\
\hline 2010 & Apple iPad - First commercially successful tablet computer \\
\hline 2012 & Apple iPad Mini - First small tablet computer from Apple \\
\hline
\end{tabular}

[13] pointed out that the technological advances have allowed mobile technologies to perform sophisticated operations, while manufacturers are constantly developing new devices that can handle new technical demands. Therefore, mobile technologies, particularly tablets and smartphones, have become powerful enough to compete and override PCs and laptops, offering portability and a lower cost. Mobile devices nowadays can be considered all-purpose computing devices with internet connectivity that allows performing different tasks such as mobile banking, e-shopping, web surfing, and mobile learning.

A mobile device can be defined as a small handheld computer with a touch display or small keyboard. As [6] explains, the key features of mobile devices are the versatility and mobility, as they can be used in different situations and settings, being easily carried around, supporting activities such as exploring outdoors. The adoption of mobile technologies is mainly influenced by three main factors: the age of the potential adopter, the technology self-efficacy, and the cultural origin, as this last one can define the role of usage [14]. Another relevant characteristic is the usability, that refers to the ease of use of mobiles technologies.

[15] estimated that by the end of $201682 \%$ of the mobile phones used worldwide would be smartphones, which represents $12 \%$ more than during 2015 . The change is particularly in emerging markets such as China or India. In those countries, people is changing from mobile phones to basic smartphones that can fulfill their needs at a lower cost (Atwal, 2017).

[16] identified five different kinds of mobile devices:

iPod - A portable media player that allow users to download various types of material such as podcast, audio,e and video, also enabling file sharing between users. However, it does not provide interactivity. The screen size is also a negative aspect as it can difficult to read big amounts of data [16] .

Personal Digital Assistant (PDA) - It combines the internet connectivity with the capabilities of a computer, having a significant processor power, and internet connec- 
tivity that allows web access [16]. The PDA could include word processing tools, dictionaries and allows the user to play both audio and video, supporting interactive group learning. Its main advantage is the possibility to introduce text via a screen keyboard having as a disadvantage the small screen and limited storage capacities [16].

Smartphone - This mobile device can be considered a hybrid device that combines the characteristics of a PDA with the abilities provided by a cell phone. It supports internet access at the time that integrates several features such as telephone, camera, and $\mathrm{mp} 3$ player. The smartphones allow storing data, supporting interactive learning and global collaboration. The main advantage of this device is its portability. However, the small screen can difficult to read a large amount of text. Another disadvantage is the price of advanced equipment [16].

Tablet PC - [16] consider that this device is the most functional of all mobile technologies. It integrates the features of a PC and network support, allowing functions like web surfing, word processing, and VoIP connections. Tablet PCs offer learning advantages such as multi-functionality and mobility, motivating independent learning and developing creativity [1].

Others - such as $\mathrm{mp} 3$ player, pen drive, and handphone. These devices have a principal advantage that they are light and compact, having a long battery life. However, they do not allow any interactivity options [16].

\subsection{Mobile learning}

The concept of mobile learning, or m-learning, has been tried to be defined by several authors. Some authors consider m-learning as a form of e-learning that is supported by the use of mobile devices such as tablets and smartphones [17]. Others regards research into mobile learning as 'the study of how the mobility of learners, augmented by personal and public technology, can contribute to the process of gaining knowledge, skills and experience' [18]. From the perspective of [19] and [20] mlearning has five principal characteristics:

1. portability: it allows to transfer the learning to any possible environment, facilitating the access to information and motivating the student to investigate and learn from experience

2. accessibility: information can be access anywhere and anytime

3. personalized: it can be adapted and customized to different learning needs and styles

4. social connectivity that increases communication and collaboration between several learners

5. increases learning motivation both in the formal and informal context

Mobile learning differs from traditional education not only because of the integration of mobile technologies. Mobile enhanced learning can work in both formal and informal environments, as well as promote both individualized and collaborative network learning. Therefore, it is possible to transform the traditional teachercentered instruction into one focused on the learner [20]. The use of mobile technolo- 
gies also promotes an informal learning process outside the classroom environment, allowing to learn without teacher support.

M-learning is a broad area that is still being explored. Hence, it is possible to research the impact of mobile learning in different areas.

\subsection{Research on the use of technology to support second language learning}

Use of computers for second language learning. Computer-assisted language learning (CALL) have been available for second language learners since the second half of the 21 century. The evolution of CALL is divided, according to [21], in three different stages known as behavioristic phase, communicative phase, and integrative stage.

In the behavioristic phase, CALL focused on repetitive material that was attentive to vocabulary, grammar and translation tests [21]. During this phase, CALL offered students of a second language the advantage of having material prepared on an individualized basis, which was available whenever it was needed and which allowing repetition. During the 70's and 80's, CALL evolved into its communicative phase. During this phase, the computer is seen as a tutor that allows learners the possibility to practice their second language skills through the use of language programs and games. CALL focused on training language proficiency such as conversation, written task, and critical thinking [21].

CALL current state is known as the integrative phase. It is based on the use of multimedia and internet for digitally supporting learning, shifting from a teacher-centered to a learner-center classroom. This learning environment can integrate different activities that support the development of language skills, increasing the motivation of the learner and decreasing the learning stress and anxiety. The access to many resources also proportionates a high degree of control over the learning process, improving the quality of education [21] [22].

Mobile assisted second language learning. Mobile assisted language learning can be seen as a subset of both m-learning and CALL [23], becoming a relevant research area as support to second language learning. Mobile-assisted second language learning (MASLL) offers the learners the advantages of mobile technology such as flexibility, small size, user friendliness, and a wide offer set of mobile applications [10] [23]. MASLL also provides learning opportunities that are not available in CALL, such as language learning through real life situations, mobility, learning over time and self-regulated learning. Other advantages are increased motivation, autonomy, and social interaction as well as decreased time for formal learning [23].

[24] pointed out that MASLL allows students to interact with different language learning software as well as with real persons such as peers and teachers. The increased collaboration allows the learners to get feedback from peers and learn to critically analyze their current skills and progress. The use of m-technology and access to apps can also contribute to the development of creative and interactive learning material that is designed for learners based on their needs. As a result, the learner will be empowered to control his/her own learning process [25]. Research has shown that 
mobile technologies facilitate the acquisition of L2 skills and linguistic knowledge, with a particular focus on vocabulary acquisition, listening comprehension, grammatical accuracy and speaking proficiency [10] [25].

\section{Method}

\subsection{Data collection}

Databases searched. The electronic databases and journals selected for this review are: ACM (Association for Computing Machinery), IEEE (Institute of Electrical and Electronics Engineers), ERIC (Education Resources Information Center), JSTOR, ScienceDirect, SAGE Journal Online, Inderscience Online and Wiley online library.

Searched terms. The search terms used for this paper can be divided into two groups. The first group includes terms that relate to mobile technologies or mobile learning. The search words in this set include "mobile technologies", "mobile learning", "mobile assisted learning", "m-learning", "mobile assisted language learning", "MALL", "mobile devices". The second group clusters terms related to second language learning: "second language", "second language acquisition", "second language learning". The search was performed by using the next query:

("mobile learning" OR "m-learning" OR "mobile assisted" OR "mobile assisted language learning" OR "MALL" OR "mobile technologies" OR "mobile devices") $A N D$ ("second language" OR "second language learning" OR "second language acquisition")

The previous query would allow the database to look for any kind of combination between any term of group one and any search phrase of the second set, such as "mobile learning AND second language acquisition" or "mobile devices AND second language".

Selection of articles for inclusion in the review. To be considered appropriate for this review, the research articles have to fulfill the following inclusion criteria:

- The article must be an empirical study.

- The investigation has explicitly address second language learning or second language acquisition, as well as the use of mobile technologies here defined as smartphones and tablets.

- The article has to be published in journals or conference proceedings published between 2010 and 2017. The time frame was defined considering the introduction of the iPad in the market during 2010 as the first commercial tablet computer, which is a central mobile technology to be considered in this review.

- The articles must be written in English.

- The articles must have an abstract. The abstract will be used to select relevant papers during the systematic review process.

The review focus only on mobile technologies, therefore, any article that addresses the use of laptops or computer-assisted language learning (CALL) will be excluded as they are not considered a mobile device. 
Papers identified and selected. The total number of research articles that were identified were 1424. The number reduced considerably after applying the inclusion and exclusion criteria to 52 selected articles. Table 2 presents the number of articles per database after applying the inclusion and exclusion criteria. Most of the articles were found in the database ERIC (48.1\%) followed by ScienceDirect $(17,3 \%)$ and JSTOR (15.4\%).

Table 2. Total number of articles identified in databases before and after applying inclusion and exclusion criteria

\begin{tabular}{|l|c|c|}
\hline \multicolumn{1}{|c|}{ Database } & \multicolumn{2}{c|}{ Frequency } \\
\hline & Initial Search & After inclusion and exclusion criteria \\
\hline ACM & 13 & 3 \\
\hline IEEE & 21 & 5 \\
\hline ERIC & 311 & 25 \\
\hline JSTOR & 48 & 8 \\
\hline ScienceDirect & 50 & 9 \\
\hline SAGE Journal Online & 225 & 0 \\
\hline Wiley Online Library & 732 & 0 \\
\hline Inderscience & 24 & 2 \\
\hline Total & 1424 & 52 \\
\hline
\end{tabular}

SAGE Journal Online, the International Review and Wiley Online presented a high number of incidences after the first initial search. The exclusion criteria eliminated from the selection most of the documents as they were related to CALL. Other articles did not fulfill the selection criteria as they considered laptops as mobile devices or focused on the use of mp3 players.

\subsection{Data analysis}

Coding. The papers that fulfill the inclusion criteria will be coded as following:

- Education form and level: primary school, secondary school, informal learning. The aim of those codes is to have an overview of the educational level and form (formal and informal) that have been subject of research. It also helps to determine potential research areas and research gaps.

- Research design: how was the research questions studied. The codes allow determining the main research methodologies used within the studies.

- Location: which country the study was conducted. The location of the studies gives an overview of the countries that have been more active in mobile second language learning. It also helps to determine if the particularities of the country influence the outcomes of the investigations performed.

- Context: Classroom, Indoors (non-classroom), Outdoors, Across indoors and outdoors. The codes explain in which context technology is mainly used and how it is used. 
- Role of technology: utilized functionality and affordance. The codes help to detect how and what technology (hardware and software) is used for second language learning purpose. At the same time, they contribute to detecting which technologies are more accessible to students.

- Pedagogical practice: how was language learning pedagogically enacted. The codes help to identify pedagogical scenarios/activities in which mobile technologies are used for supporting second language learning.

- Learning outcomes. The category provides an overview of the impact of the use of mobile devices in the process of second language learning.

To assess inter-rater reliability with respect to the coding of the papers, a subsample of 27 of the 54 papers $(50 \%)$ was coded independently by one of the coders. The inter-rater reliability (r) was .93 , showing good agreement between the two coders.

\section{$4 \quad$ Results}

\subsection{Education form and level}

Table 3 indicates the educational form and the educational level reported on in the selected research articles. Formal education is the most researched educational form, being studied in $41(78,8 \%)$ papers, indicating the incorporation of mobile learning practices into the L2 curricula. Informal education is addressed only in $8(15,4 \%)$ research articles. The last three documents $(5.8 \%)$ have a blended focus on both formal and informal learning as the purpose of two of them was to explore the attitudes of students and/or teachers towards MASLL in general terms whereas the last document explored the use of both formal and informal MASLL between fifth graders.

Table 3. Education form by educational level studied in the selected articles

\begin{tabular}{|l|c|c|c|c|}
\hline & \multicolumn{3}{|c|}{ Education form } & Total \\
\hline \multicolumn{1}{|c|}{ Education Level } & Formal & Informal & Blended & \\
\hline Kindergarten/Preschool & 1 & & & 1 \\
\hline Primary School & 11 & 2 & 1 & 14 \\
\hline Secondary School & 6 & & & 6 \\
\hline Higher Education & 20 & 3 & 2 & 25 \\
\hline Blended (2 education levels) & 1 & 2 & & 3 \\
\hline Non specified & 2 & 1 & & 3 \\
\hline Total & 41 & 8 & 3 & 52 \\
\hline
\end{tabular}

The data indicates that a large portion of the studies, 20 papers $(38 \%)$, have focused mainly on L2 learners within formal higher education. The second most addressed educational level is primary school (14 studies, $27 \%$ of the total selected papers), particularly in a formal context $(22 \%)$. Other educational levels identified were kindergarten/preschool (2\%), secondary school $(12 \%)$ or mixed groups $(6 \%)$ 
formed by primary and secondary school L2 learners or secondary school and higher education students. The last group is based on three research articles which participants were L2 students in language schools with an age range from 16 years old and up.

\subsection{Employed study design}

Table 4 shows the different research methodologies used in MASLL projects. The most popular design was quasi-experiments (39\% of the papers). The approach is characterized by the utilization of a pre-test and a post-test for measuring the L2 proficiency of the participants, who were part of non-randomized control and experimental groups. Survey was identified as the second most used research design, used in $21 \%$ of the documents, followed by the mixed methods approach (15\%) case studies $(8 \%)$ and experimental design (8\%). A minority of papers reported Design-Based Research (2\%) and pure qualitative methodologies (4\%).

Table 4. Research design used

\begin{tabular}{|l|c|c|}
\hline \multicolumn{1}{|c|}{ Research Design } & Frequency & \% \\
\hline Quasi-experimental & 20 & $38,5 \%$ \\
\hline Survey & 11 & $21,2 \%$ \\
\hline Mixed Methods & 8 & $15,4 \%$ \\
\hline Case study & 4 & $7,7 \%$ \\
\hline Experimental & 4 & $7,7 \%$ \\
\hline Correlational & 2 & $3,8 \%$ \\
\hline Qualitative & 2 & $3,8 \%$ \\
\hline Design Based Research & 1 & $1,9 \%$ \\
\hline Total & 52 & $100,0 \%$ \\
\hline
\end{tabular}

\subsection{Location}

presents an overview of the countries where MASLL research is taking place. The data shows that Asia is the most active region representing the $65 \%$ of the papers included in this study. Taiwan has shown itself as an active country with a clear interest in MASLL research, producing 14 studies (27\%), followed by Saudi Arabia, Malaysia, and Singapore with three papers each $(6 \%)$.

The table also indicates that Europe's involvement in MASLL research is represented by $27 \%$ of papers. The UK has taken the leadership of the region by producing four research projects (one of them in collaboration with Italy and Norway), followed by Netherlands and Turkey with two documents each. America was the less active geographic area with only four research projects, representing $8 \%$ of the conducted studies. 
Table 5. Countries where the selected studies have been performed

\begin{tabular}{|l|c|l|c|c|c|}
\hline \multicolumn{1}{|c|}{ Asia } & & \multicolumn{1}{c|}{ Europe } & & America & \\
\hline \multicolumn{1}{|c|}{ Country } & Frequency & \multicolumn{1}{c|}{ Country } & Frequency & Country & Frequency \\
\hline Taiwan & 14 & UK & 3 & USA & 2 \\
\hline Saudi Arabia & 3 & Netherlands & 2 & Brazil & 1 \\
\hline Malaysia & 3 & Turkey & 2 & Canada & 1 \\
\hline Singapore & 3 & Belgium & 1 & & \\
\hline China & 2 & China/Sweden & 1 & & \\
\hline India & 2 & Germany & 1 & & \\
\hline Iran & 2 & Hungary & 1 & & \\
\hline Kuwait & 2 & Russia & 1 & & \\
\hline Japan & 1 & Spain & 1 & & \\
\hline Kazakhstan & 1 & Italy/Norway /UK & & & \\
\hline Thailand & 1 & & 14 & & \\
\hline Total & 34 & &
\end{tabular}

\subsection{MASLL context}

Data in Table 6 shows that mobile devices for second language learning are mainly used indoors $(70 \%)$ in three different contexts: classroom $(25 \%)$, non-classroom $(17 \%)$, and across both of them $(27 \%)$. The use of MASLL across indoors and outdoors represents $27 \%$ of the conducted studies. These studies are characterized for mixing both learning activities indoors with task-based activities in a real world context, supporting the idea of situated and ubiquitous learning. However, the use of MASLL only in outdoors contexts has not been explored extensively as it only represents the $4 \%$ of the total.

Table 6. Context of learning activities

\begin{tabular}{|l|c|c|}
\hline \multicolumn{1}{|c|}{ Context } & Frequency & \% \\
\hline Classroom & 13 & $25,0 \%$ \\
\hline Indoors (non classroom) & 9 & $17,3 \%$ \\
\hline Indoors (classroom and non classroom) & 14 & $26,9 \%$ \\
\hline Total Indoors & 36 & $69,2 \%$ \\
\hline Outdoors & 2 & $3,8 \%$ \\
\hline Across indoors and outdoors & 14 & $26,9 \%$ \\
\hline Total & 52 & $100,0 \%$ \\
\hline
\end{tabular}

\subsection{Role of Technology}

Mobile devices and MASLL. Mobile phones are the most popular devices used for MASLL purposes $(67 \%)$. The most representative mobile phone is the smartphone (44\%), while PDAs are represented by only $4 \%$. Few studies used tablets $(14 \%)$. 
However, there is a higher incidence of studies that used both mobile phones and tablets for MASLL purposes (19\%).

Regarding the utilization of a particular operating system, Android showed the higher representation with $19 \%$, followed by iOS (10\%) and Windows Mobile (4\%). Three studies that used more than one type of mobile device indicated the use of both Android and iOS (6\%). There is, however, a high occurrence of research papers that did not specify the type of operating system used during the research $(62 \%)$.

Table 7. Devices identified in the selected articles by operating system

\begin{tabular}{|c|c|c|c|c|c|c|}
\hline \multirow[b]{2}{*}{ Device } & \multicolumn{5}{|c|}{ Operating System } & \multirow{2}{*}{$\begin{array}{c}\text { Total by type of } \\
\text { device }\end{array}$} \\
\hline & Android & $i O S$ & Android/iOs & Windows & Not Specified & \\
\hline \multicolumn{7}{|l|}{ Mobile phone } \\
\hline Smartphone & 9 & 2 & & 1 & 11 & 23 \\
\hline PDA phone & & & & 1 & 1 & 2 \\
\hline Non specified & & & & & 10 & 10 \\
\hline Subtotal mobile phones & 9 & 2 & 0 & 2 & 22 & 35 \\
\hline Tablet PC & & 3 & & & 4 & 7 \\
\hline \multicolumn{7}{|l|}{ Blended } \\
\hline Smartphone/Tablet PC & 1 & 1 & 2 & & 6 & 10 \\
\hline Total by OS & 10 & 6 & 2 & 2 & 32 & 52 \\
\hline
\end{tabular}

Software and mobile applications used for MASLL purposes. Mobile applications employed in the researched documents were grouped into four categories: educational applications, mobile messenger/SMS applications, audio/video applications, and web browsers. $75 \%$ of the reviewed documents included only applications in one category while the remaining $25 \%$ used more than one category during their research (detailed information in Table 8). Educational applications presented the highest incidence with 22 papers (43\%), 17 of them specifically developed for the research $(33 \%)$. The rest of the applications identified were not developed specifically for learning purposes but were used to support MASLL. Mobile Messengers/SMS applications represented $12 \%$ of the sample, while audio/video player apps and web browser were $6 \%$ each. $10 \%$ of the papers did not specify the mobile applications used for MASLL.

Table 9 shows in detail the mobile applications used in the 13 studies that have been coded in more than one category. $46 \%$ of the studies included the use of web browsers as part of the learning practices, followed by the use of educational applications (39\%). The next most used applications are Mobile messengers/SMS (31\%), Audio/Video recorders (31\%), Audio/Video players $(23 \%)$ and Online storage/Collaboration platforms (23\%). Some research papers also included Blogs apps (15\%), QR scanner apps (15\%), free multimedia apps $(8 \%)$, E-book readers $(8 \%)$, Facebook app (8\%), E-mail apps (8\%), and text to speech apps (8\%). 
Table 8. Mobile applications used

\begin{tabular}{|l|c|c|}
\hline \multicolumn{1}{|c|}{ Software type } & Frequency & \% \\
\hline Educational applications & & \\
\hline Developed for the study & 17 & $32,7 \%$ \\
\hline Others & 5 & $9,6 \%$ \\
\hline Total Educational applications & 22 & $42,3 \%$ \\
\hline Mobile Msg /SMS & 6 & $11,5 \%$ \\
\hline Audio/Video player & 3 & $5,8 \%$ \\
\hline Web browser & 3 & $5,8 \%$ \\
\hline Non specified & 5 & $9,6 \%$ \\
\hline Subtotal studies using a single type of application & 39 & $75,0 \%$ \\
\hline Studies using more than one type of application & 13 & $25,0 \%$ \\
\hline Total & 52 & $100,0 \%$ \\
\hline
\end{tabular}

Table 9. Studies using more than one type of application

\begin{tabular}{|l|c|c|}
\hline \multicolumn{1}{|c|}{ Software type } & Frequency & $\%$ \\
\hline Educational applications & & $30,8 \%$ \\
\hline Developed for the study & 1 & $7,7 \%$ \\
\hline Others & 5 & $38,5 \%$ \\
\hline Total educational applications & 6 & $46,2 \%$ \\
\hline Web browser & 4 & $30,8 \%$ \\
\hline Mobile Msg /SMS & 4 & $30,8 \%$ \\
\hline Audio/Video recorder & 3 & $23,1 \%$ \\
\hline Audio/Video player & 3 & $23,1 \%$ \\
\hline Online storage / Collaboration platform & 2 & $15,4 \%$ \\
\hline Blog app & 2 & $15,4 \%$ \\
\hline QR Scanner app & 1 & $7,7 \%$ \\
\hline Free multimedia apps & 1 & $7,7 \%$ \\
\hline E-book reader & 1 & $7,7 \%$ \\
\hline Facebook & 1 & $7,7 \%$ \\
\hline Email & 1 & $7,7 \%$ \\
\hline Text to Speech & 1 & $7,7 \%$ \\
\hline Non specified free apps & & \\
\hline
\end{tabular}

Hardware used for MASLL purposes. The data in Table 10 shows how the different mobile device's hardware is mainly used for MASLL. The increased use of Internet as a support for learning activities is demonstrated by the importance of the use of devices that can offer Wi-Fi and/or mobile internet capabilities $(60 \%)$ helping the students to access learning material anytime anywhere. Using the wi-fi allows the learner to access learning material and other online resources such as dictionaries on ubiquitous basis [26]. It is also used to support online communication [27], as well as to share self-created material [28]. 
Built-in microphone (27\%), built-in camera (25\%) and the built-in speakers $(23 \%)$ represent the next more used components, as they allow L2 learners to create their own learning material and perform task-based activities to develop different L2 skills.

The built-in microphone supports all kind of task that involve the oral skill. It is used to record text or dialogues that will be sent after to the teacher or other students as part of a particular task [28]. Furthermore, by utilizing speech recognition software students are, for instance, supported to improve their pronunciation [29]. The microphone is also used as a tool to communicate with other peers and teachers [30], as well as for the creation of multimedia material [31].

The built-in camera allows the L2 learners to take photos of relevant material such as vocabulary lists [31]. The camera can also be used to create flashcards [32], and scan QR codes as part of learning tasks [33]. Other hardware components presented were GPS (8\%), SD memory cards for storing multimedia material $(4 \%)$, and other components $(6 \%)$ such as the use of projectors. However, $14 \%$ of the papers did not specify the hardware used for MASLL purposes.

Table 10.

Hardware used

\begin{tabular}{|l|c|c|}
\hline \multicolumn{1}{|c|}{ Hardware type } & Frequency & \% \\
\hline Wi-Fi/Mobile internet & 31 & $59,6 \%$ \\
\hline Built-in microphone & 14 & $26,9 \%$ \\
\hline Built-in camera & 13 & $25,0 \%$ \\
\hline Built-in speakers & 12 & $23,1 \%$ \\
\hline Non specified & 7 & $13,5 \%$ \\
\hline GPS & 4 & $7,7 \%$ \\
\hline Others & 3 & $5,8 \%$ \\
\hline SD memory card & 2 & $3,8 \%$ \\
\hline
\end{tabular}

\subsection{Pedagogical practice}

Pedagogical practices found in the selected articles focus on improving L2 proficiency and were clustered into four subcategories: general practices to improve L2 proficiency, vocabulary learning, speaking/listening skills and reading/writing skills.

Table 11 presents in detail the frequency of documents discussing the different subcategories. The table shows that the number of articles addressing practices in only one subcategory represented $46 \%$ of the total sample while the studies that addressed two or more subcategories represented $42 \%$.

Vocabulary learning is the most relevant subcategory as $54 \%$ of the analyzed documents includes it. It is discussed as a single subcategory in 12 documents (23\%) and described together with at others in $16(31 \%)$. It is also the main informal learning practice as 7 out of 8 informal learning practices involve vocabulary learning. Taking pictures for associating words with images/real objects [33], getting vocabulary list via SMS [34], creating own definitions of new words or situational vocabulary learning [35] are examples of the practices described in the reviewed research papers. 
Table 11. Pedagogical practices for improving L2 proficiency

\begin{tabular}{|c|c|c|c|c|c|c|c|c|}
\hline & \multicolumn{6}{|c|}{ Educational Form } & \multirow{3}{*}{$\begin{array}{c}\text { Total } \\
\text { Frequency }\end{array}$} & \multirow[b]{3}{*}{$\%$} \\
\hline & \multicolumn{2}{|c|}{ Formal } & \multicolumn{2}{|c|}{ Informal } & \multicolumn{2}{|c|}{ Blended } & & \\
\hline & Frequency & $\%$ & Frequency & $\%$ & Frequency & $\%$ & & \\
\hline $\begin{array}{l}\text { General L2 profi- } \\
\text { ciency (GP) }\end{array}$ & 10 & $19,2 \%$ & & & & & 10 & $19,2 \%$ \\
\hline $\begin{array}{l}\text { Vocabulary learn- } \\
\text { ing (VL) }\end{array}$ & 7 & $13,5 \%$ & 4 & $7,7 \%$ & 1 & $1,9 \%$ & 12 & $23,1 \%$ \\
\hline $\begin{array}{l}\text { Speaking } \\
\text { /Listening skills } \\
\text { (S/L) }\end{array}$ & 2 & $3,8 \%$ & & & & & 2 & $3,8 \%$ \\
\hline $\begin{array}{l}\text { Reading/Writing } \\
\text { skills }(\mathrm{R} / \mathrm{W})\end{array}$ & & & & & & & & \\
\hline $\begin{array}{l}\text { More than one } \\
\text { learning skill }\end{array}$ & & & & & & & & \\
\hline $\mathrm{GP}+\mathrm{VL}$ & 5 & $9,6 \%$ & 2 & $3,8 \%$ & & & 7 & $13,5 \%$ \\
\hline $\mathrm{GP}+\mathrm{S} / \mathrm{L}$ & 3 & $5,8 \%$ & 1 & $1,9 \%$ & & & 4 & $7,7 \%$ \\
\hline $\mathrm{GE}+\mathrm{R} / \mathrm{W}$ & 2 & $3,8 \%$ & & & & & 2 & $3,8 \%$ \\
\hline $\mathrm{GP}+\mathrm{VL}+\mathrm{S} / \mathrm{L}$ & 1 & $1,9 \%$ & & & & & 1 & $1,9 \%$ \\
\hline $\mathrm{GP}+\mathrm{VL}+\mathrm{R} / \mathrm{W}$ & 1 & $1,9 \%$ & & & & & 1 & $1,9 \%$ \\
\hline $\mathrm{VL}+\mathrm{S} / \mathrm{L}$ & 3 & $5,8 \%$ & 1 & $1,9 \%$ & & & 4 & $7,7 \%$ \\
\hline $\mathrm{VL}+\mathrm{R} / \mathrm{W}$ & 3 & $5,8 \%$ & & & & & 3 & $5,8 \%$ \\
\hline Total & 37 & $71,2 \%$ & 8 & $15,4 \%$ & 1 & $1,9 \%$ & 46 & $88,5 \%$ \\
\hline
\end{tabular}

MASLL practices focused on improving general skills are the second in frequency, as they are described in 25 documents (48\%). Task-based language learning to improve particular skills [26], repetition by using mobile learning applications anytime anywhere [36] and the creation of personalized learning material by using video recording, images and photos [32] are examples of practices in this subcategory.

The proportion of documents describing practices to improve the Speaking/Listening and Reading/Writing skills is low compared with the ones focusing on vocabulary learning or improving general skills. Activities focused on improving the speaking/listening proficiency are mentioned in a total of 9 documents ( 2 single studies and seven mixed) representing $17 \%$ of the total. Some examples of practices included in this cluster are the use of podcast [37] and videos with captions for improving listening comprehension, recordings of oral presentations to improve oral skills, and the use of task-based activities to practice L2 with native speakers in real situations [27].

Improving the reading/writing proficiency is the less addressed subcategory. There are no papers that focus only on the development of those skills, being always described together with at least one of the other three subcategories. Writing in blogs [32], using online dictionaries for improving the writing skill [11], and reading personalized material [38] are described as some of the activities to improve reading and writing proficiency in L2. 


\subsection{Learning Impact}

The codes concerning the learning impact found in the different reviewed articles were grouped into three different categories: knowledge acquisition and understanding, affective and/or motivational impact, and impact on the social skills. Table 12 shows the categories mentioned above by the type of research design. The $46 \%$ of the documents presented learning outcomes of only one category while $54 \%$ was formed by studies that reported a learning impact in two or more categories.

Table 12. Type of learning impact by research design

\begin{tabular}{|c|c|c|c|c|c|c|c|c|c|c|}
\hline & \multicolumn{8}{|c|}{ Research Design } & \multirow[b]{2}{*}{$\begin{array}{c}\text { Fre- } \\
\text { quency }\end{array}$} & \multirow{2}{*}{ 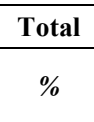 } \\
\hline & $\begin{array}{l}\text { Quasi } \\
\text { Exp. }\end{array}$ & Survey & $\begin{array}{c}\text { Mixed } \\
\text { Methods }\end{array}$ & $\begin{array}{l}\text { Case } \\
\text { Study }\end{array}$ & Exp. & Correl. & $D B R$ & Qual. & & \\
\hline $\begin{array}{l}\text { Knowledge acquisi- } \\
\text { tion and understand- } \\
\text { ing (KA) }\end{array}$ & 8 & 3 & 1 & & 4 & & & & 16 & $30,8 \%$ \\
\hline $\begin{array}{l}\text { Affective and/or } \\
\text { motivational impact } \\
(\mathrm{AM})\end{array}$ & & 4 & 1 & 2 & & 1 & & & 8 & $15,4 \%$ \\
\hline Social Skills (SS) & & & 1 & 1 & & & & 1 & 3 & $5,8 \%$ \\
\hline \multicolumn{11}{|l|}{ More than one LI } \\
\hline $\mathrm{KA}+\mathrm{AM}$ & 6 & 3 & & & & 1 & & & 10 & $19,2 \%$ \\
\hline $\mathrm{KA}+\mathrm{SS}$ & 4 & & 3 & 1 & & & 1 & 1 & 10 & $19,2 \%$ \\
\hline $\mathrm{KA}+\mathrm{AM}+\mathrm{SS}$ & 2 & & 1 & & & & & & 3 & $5,8 \%$ \\
\hline $\mathrm{AM}+\mathrm{SS}$ & & 1 & 1 & & & & & & 2 & $3,8 \%$ \\
\hline Total & 20 & 11 & 8 & 4 & 4 & 2 & 1 & 2 & 52 & $100,0 \%$ \\
\hline
\end{tabular}

Knowledge acquisition and understanding outcomes presented the highest proportion compared with the other groups as they were reported in 39 papers $(75 \%)$. In those cases, the papers also presented outcomes in other categories such as motivational impact. The learning impact in this category describes how the use of different mobile assisted practices supports L2 learning by increasing the language proficiency both in general aspects as in particular skills. Examples of this outcomes include:

- The interaction with the real world enhances the language skills and increase the learning performance [27].

- The use of mobile applications helps L2 learners to remember new vocabulary for a longer time compared with traditional learning practices [39].

- The association of words with images and/or real objects helps the L2 learner to understand the meaning of the word, increasing they vocabulary [40].

- The use of podcasts increases the listening proficiency of L2 students [37].

- These of MASLL in a real world context helps to improve the oral performance of L2 learners, particularly when practicing with native speakers [41].

- L2 learners benefit from adaptive reading material by improving the reading effectiveness and comprehension, reducing the cognitive load and improving the student satisfaction [38]. 
The group formed by affective and/or motivational outcomes is the second most representative with a proportion of $42 \%$ of the total sample. The use of mobile applications helps to increase the student motivation to learn [42] which also have a direct impact on language proficiency. The use of MASLL also helps to reduce learners' anxiety [37] and decrease cognitive load.

The outcomes related to social skills are found in the $35 \%$ of the coded papers. The learning outcomes identified in the coded papers focus on describing how the use of MASLL influences the students' collaboration. Some findings support that the use of mobile messenger applications, blogs and social networks by L2 students supports the development of collaborative skills [43]. Another impact is collaborative peer coaching as a form to reduce the gaps between L2 learners with high and low proficiency [44].

\section{Discussion}

As it was stated at the beginning of the document, the aim of this research was to investigate the use of mobile technologies to support L2 learning by examining the current research trends. By using the research terms, we identified 1424 papers that were related to MALL and SLL. This number was reduced to 52 documents after applying the inclusion and exclusion criteria as it was important to identify only the papers that addressed the specific use of MASLL since 2010. For assuring the quality of the papers, only published studies, in term of journals and conference papers, were considered.

\subsection{Major trends in studies about the use of mobile technologies as a tool for second language learning.}

During the review, it was possible to see that most of the selected papers focused on the use of MASLL learning within formal education. Mobile devices have been included as a part of language courses curricula, using them as support in the classroom. In other cases, the students are encouraged to use mobile devices for performing activities after class to repeat the material seen during class. Current studies have prioritized to explore the effects of MASLL within students in higher education, followed in minor proportion by primary school learners, representing in total $75 \%$ of all the coded papers, being secondary school students.

Regarding the countries where MASLL is seen as an active research topic, is possible to see that most of the research is done in Asia. $46 \%$ of the studies has taken place in Easter Asian countries, showing the importance of technology adoption for learning purposes in the region. The research has focused mainly on the use of MASLL for supporting the learning of English and Chinese as second and/or foreign language. The other regions that have performed research on this topic have not present the same activity. 


\subsection{Major methodologies and outcomes identified}

The reviews papers indicated that the most popular methodology in research projects on MASLL is the quasi-experimental design, representing $40 \%$ of all coded papers. The main characteristic of the coded documents that used this methodology is the lack of randomization in the control and experimental groups, and the use of pretest and post-test that allows measuring if the utilization of a mobile learning had an impact on the language skills of the L2 learners that participated in the students. Therefore, the outcomes related to this approach are all related to knowledge acquisition and understanding.

Survey and mixed methods are the two following major methodologies. Surveys characterized for exploring the attitudes, opinions, and perceptions of L2 learners regarding their experience with MALL. On the other hand, the use of mixed methods methodology allowed the researchers to use both quantitative and qualitative data collection methods. Consequently, it was possible to measure both the effects of the use of MASLL as well as the attitudes of the L2 students that participated in the research. The research designs discussed above represents $75 \%$ of all the coded documents.

Concerning the learning impact of MASLL, the outcomes identified were mainly related the effects of mobile learning on the students' proficiency in the target language. A large number of the coded papers indicated that the L2 learners that were involved in MASLL activities improved their language proficiency compared with the students using traditional practices. Most of them referred to a general proficiency, followed by increased vocabulary learning. The remaining documents focused on the development of the reading, oral and listening skills.

The second group of outcomes focused on the impact of attitudes and/or motivation of the L2 students and in some cases on the teachers. In this regards, [27] pointed out that higher motivation has a positive influence particularly in students with medium/low language proficiency. Other findings in this category showed that the flexibility to access learning materials in different context transforms the L2 students from passive to active.

Finally, the outcomes related to social skills indicated that the use of mobile devices in teams, particularly when two or more users share one device, increased the social interaction between learners. Increasing communication between L2 learners gives the possibility to discuss learning material, and creates a collaborative environment that support development of collaborative skills. In cases when the collaboration takes place between students with different language proficiency, the main impact is the use of a collaborative coaching where students with high L2 proficiency helped medium and low proficiency students to learn. This activity contributes to reduce the gap between high and low achievers.

\subsection{Role of mobile technologies on second language learning}

This review showed that language learning is supported by mobile devices as well as different mobile applications. It is a common practice to use educational applica- 
tions, particularly to support vocabulary learning. There are several free applications in the market that can support MASLL activities. However, many non-educational applications and software such as audio/video players is used to support MASLL. In this regards, the built-in components (camera, microphone, and speakers) are relevant tools to create different kind of multimedia material, as well as support communication via messenger applications.

Pedagogical practices supported by mobile technologies. The coded papers showed that MASLL pedagogical practices focus on the improvement of the L2 proficiency, with a particular focus on vocabulary learning. L2 learners can improve their vocabulary by the use of different educational applications such as context-aware games that allow play and learn in a real environment. Another common practice for vocabulary learning is the association of words with images and/or real objects both in a classroom or in the real world.

MASLL also supports ubiquitous learning. Students can access learning material outside the classroom being able to learn in different context, for example during transport time. Another practice is the use of task-based activities supported by mobile devices. L2 instructors can design different task for improving a specific skill, such as the use of podcast for improving the listening comprehension or using social networks for practicing the writing skill. The activities can also include interactions with the real world, such as interacting with native speakers to improve the oral skills. The creation of personalized material is another pedagogical practice that can help the L2 student to increase proficiency in the target language. The student can create material that fits their learning style and needs by using mobile devices. At the same time, it is possible to share this material with other students by using mobile applications, blogs, and social networks, increasing the collaboration between peers and teachers.

\subsection{Context where mobile technologies are utilized for second-language learning}

All the technological resources that have been discussed previously has developed a variety of pedagogical practices supported by mobile technology that are mainly taking place indoors, both in a classroom and a non-classroom context. The use of mobile devices has also allowed extending the SLL task outdoors, generating a blended environment that supports situated and ubiquitous second language learning. There is, however, a lack of studies that focus only on MASLL outdoors, as most of the practices in an outdoors context observed also include tasks indoors.

\subsection{Major similarities and contradictions of these studies}

Even if each project studied MASLL from a different perspective, all of them agree on the positive impact of mobile devices for enhancing the L2 learning process. The result can be seen as an improvement in the proficiency of the target language, in the learning motivation, or in both of them. There was no research finding showing a negative impact on performance as a result of using mobile devices. At the same time, all studies that presented results related to collaborative practices agreed that working 
in groups is beneficial for L2 learners, creating a motivating and enjoyable environment. Another major similarity is the increased attention in the use of educational software within MASLL. Furthermore, there is an increasing interest in the creation of software that can specifically adapt to the needs of the L2 students or the particular objectives of course curricula.

\subsection{Which are the gaps not addressed in these studies?}

The current systematic review has explored the main tendencies of current MASLL research which has taken place mostly in Asia and Europe. The studies in the American region has been minimal, for instance in Latin America where only one document was identified. Therefore, there is still a lot to investigate regarding the effects of mobile devices for second language learning in this region, as well as how MASLL can support second language learning in African countries.

Most of the studies have tried to show the impact of the use of mobile technologies in second language learning, focusing mainly on its integration of formal education in primary school and higher education. However, few papers have reported in the same detail how MASLL can support informal independent learning, as well as studies that focus on MASLL between secondary school learners. There is also many opportunities to explore how to develop MASLL within an outdoors context that does not involve indoors activities.

Another area that is subject to future studies is the use of MASLL for improving the reading and writing skills of L2 learners. Research has paid more attention to how the use of mobile devices can support L2 learning for improving languages skills in general terms as well as how MASLL support vocabulary learning. There are, however, few papers investigating MASLL practices that support the improvement of oral and listening skills, or the proficiency in L2 reading and writing. Additionally, the main focus on the use of smartphones has left the use of tablets for L2 learning almost unexplored, creating a gap in the technological aspect of MASLL.

\section{Conclusions}

The current study presented a snapshot of the research on mobile assisted second language learning which is representative of a state of the art up to date. The systematic review, allowed to identify not only the positive outcomes of the use of mobile technologies to support second language learning, but also the main trends within research, such as an increasing interest in the development of mobile learning applications.

The papers were coded to detect patterns within the educational form and level being studied, the major methodologies used, the context in which MASLL is taking place as well as which technology and how is being used for learning purposes. Additionally, it was reviewed the different pedagogical practices that use mobiles devices, especially smartphones, to support L2 learning and how they impact the student language proficiency, motivation, and collaboration. While most of the reviewed docu- 
ments focused on the integration of MASLL, especially among primary school and higher education students, there is still a lack of research on informal language learning. The review also showed a trend to study MASLL as a tool to improve vocabulary learning and general skills development, underrepresenting how mobile technologies can improve the reading, writing, listening and oral skills.

MASLL is an area that still needs to be studied. Further studies can be helpful to study in detail how mobile technologies can support informal language learning, as well as studies regarding pedagogical practices to improve the underrepresented language skills. Additionally, the lack of a relevant number of studies including the tablet PC gives an opportunity to explore how their particular characteristics can be useful to support SLL.

\section{$7 \quad$ References}

[1] Shamir-Inbal, T., \& Blau, I. (2016). Developing Digital Wisdom by Students and Teachers. Journal of Educational Computing Research,54(7), 967-996. https://doi.org/10.1177/ 0735633116649375

[2] Moreir, F., Ferreira, M. J., Santos, C. P., \& Durão, N. (2016). Evolution and use of mobile devices in higher education: A case study in Portuguese Higher Education Institutions between 2009/2010 and 2014/2015. Telematics and Informatics. https://doi.org/10.1016/ j.tele.2016.08.010

[3] Dunn, J., Gray, C., Moffett, P., \& Mitchell, D. (2016). 'It's more funnier than doing work': children's perspectives on using tablet computers in the early years of school. Early Child Development and Care, 1-13. https://doi.org/10.1080/03004430.2016.1238824

[4] Bentley, G. F., Turner, K. M., \& Jago, R. (2016). Mothers' views of their preschool child's screen-viewing behaviour: a qualitative study. BMC Public Health,16(1). https://doi.org/10.1186/s12889-016-3440-z

[5] Ncube, S. P., \& Suleman, H. (2014). Complementing formal learning with mobile technology outside the classroom. 2014 International Conference on Interactive Mobile Communication Technologies and Learning (IMCL2014). https://doi.org/10.1109/IMCTL. 2014.7011103

[6] Rogers, Y., Connelly, K., Hazlewood, W., \& Tedesco, L. (2009). Enhancing learning: a study of how mobile devices can facilitate sensemaking. Personal and Ubiquitous Computing, 14(2), 111-124. https://doi.org/10.1007/s00779-009-0250-7

[7] Clarke, B., \& Svanaes, S. (2015). Updated review of the global use of mobile technology in education.

[8] Nouri, J., \& Pargman, T. C. (2016). When Teaching Practices Meet Tablets' Affordances. Insights on the Materiality of Learning. In European Conference on Technology Enhanced Learning (pp. 179-192). Springer International Publishing. https://doi.org/10.1007/978-3319-45153-4 14

[9] Niño, A. (2015). Language Learners Perceptions and Experiences on the Use of Mobile Applications for Independent Language Learning in Higher Education. IAAFOR Journal of Education, 73-84.

[10] Viberg, O., \& Grönlund, Å. (2013). Cross-cultural analysis of users' attitudes toward the use of mobile devices in second and foreign language learning in higher education: A case from Sweden and China. Computers \& Education,69, 169-180. https://doi.org/10.1016/ j.compedu.2013.07.014 
[11] Van de Vyver, J (2016). The use of mobile technology in te teaching and learning of foreign languages in French speaking Belgium: the learners perspective. Retrieved from https://www.researchgate.net/publication/312497611 The use of mobile technology in the teaching and learning of foreign languages in French-speaking Belgium the lear ners $\% 27$ perspective

[12] Chartrand, R. (2016). Advantages and Disadvantages of Using Mobile Devices in a University Language Classroom. Retrieved February 13, 2017, from http://hdl.handle.net/ $\underline{11316 / 445}$

[13] Sanakulov, N., \& Karjaluoto, H. (2015). Consumer adoption of mobile technologies: a literature review. International Journal of Mobile Communications,13(3). https://doi.org/10.1504/IJMC.2015.069120

[14] Sarker, S., \& Wells, J. D. (2003). Understanding mobile handheld device use and adoption. Communications of the ACM,46(12), 35. https://doi.org/10.1145/953460.953484

[15] Atwal, R. (2017) Gartner Forecasts flat worldwide device shipments until 2018. Retrieved from http://www.gartner.com/newsroom/id/3560517

[16] Jacob, S. M. \& Issac, B. (2008). Mobile Devices and its Mobile Learning Usage Analysis, ICICWS, Lecture Notes in Engineering and Computer Science, pp.782-787

[17] Cheng, Y. (2015). Towards an understanding of the factors affecting m-learning acceptance: Roles of technological characteristics and compatibility. Asia Pacific Management Review,20(3), 109-119. https://doi.org/10.1016/j.apmrv.2014.12.011

[18] Kukulska-Hulme, A., Sharples, M., Milrad, M., Arnedillo-Sánchez, I., \& Vavoula, G. (2011). The Genesis and Development of Mobile Learning in Europe. In Parsons, D. (Ed.), Combining E-Learning and M- Learning: New Applications of Blended Educational Resources. pp. 151-177. https://doi.org/10.4018/978-1-60960-481-3.ch010

[19] Marzouki, O. F., Idrissi, M. K., \& Bennani, S. (2013). Mobile Education. Proceedings of International Conference on Advances in Mobile Computing \& Multimedia-MoMM '13. https://doi.org/10.1145/2536853.2536862

[20] Sung, Y., Chang, K., \& Yang, J. (2015). How effective are mobile devices for language learning? A meta-analysis. Educational Research Review, 16, 68-84. https://doi.org/10.1016/j.edurev.2015.09.001

[21] Dina, A. T., \& Ciornei, S. I. (2013). The advantages and disadvantages of computer assisted language learning and teaching for foreign languages. Procedia-Social and Behavioral Sciences, 76, 248-252. https://doi.org/10.1016/j.sbspro.2013.04.107

[22] Bozdoğan, D. (2015). MALL Revisited: Current Trends and Pedagogical Implications. Procedia - Social and Behavioral Sciences, 195, 932-939. https://doi.org/10.1016/ j.sbspro.2015.06.373

[23] Kim, H. \& Kwon, Y. (2012). Exploring smartphone applications for effective mobileassisted language learning. Multimedia-Assisted Language Learning, 15(1), 31-57.

[24] Azar, A. S., \& Nasiri, H. (2014). Learners' Attitudes toward the Effectiveness of Mobile Assisted Language Learning (MALL) in L2 Listening Comprehension. Procedia - Social and Behavioral Sciences,98, 1836-1843. https://doi.org/10.1016/j.sbspro.2014.03.613

[25] Kukulska-Hulme, A., \& Shield, L. (2008). An overview of mobile assisted language learning: From content delivery to supported collaboration and interaction. ReCALL,20(03). https://doi.org/10.1017/S0958344008000335

[26] Huang, Y., Huang, Y., Huang, S., \& Lin, Y. (2012). A ubiquitous English vocabulary learning system: Evidence of active/passive attitudes vs. usefulness/ease-ofuse. Computers \& Education,58(1), 273-282. https://doi.org/10.1016/j.compedu.2011. $\underline{08.008}$ 
[27] Lin, Y., Kao, C., \& Lan, Y. (2016). The effects of mobile learning on students' oral performance in Mandarin Chinese and their attitudes. International Journal of Mobile Learning and Organisation, 10, 78-101. https://doi.org/10.1504/IJMLO.2016.076191

[28] Chai, C. S., Wong, L. H., \& King, R. B. (2016). Surveying and Modeling Students' Motivation and Learning Strategies for Mobile-Assisted Seamless Chinese Language Learning. Educational Technology \& Society, 19 (3), 170-180.

[29] Jain, M., Birnholtz, J., Cutrell, E., \& Balakrishnan, R. (2011). Exploring display techniques for mobile collaborative learning in developing regions. Proceedings of the 13th International Conference on Human Computer Interaction with Mobile Devices and Services - MobileHCI'11. https://doi.org/10.1145/2037373.2037388

[30] Dogan, A. \& Akbarov, A. (2016). Teachers' Attitudes toward the Usage of Mobile Devices in EFL Classroom. European Journal of Educational Research,5(1), 11-17. https://doi.org/10.12973/eu-jer.5.1.11

[31] Hazaea, A. N., \& Alzubi, A. A. (2016). The Effectiveness of Using Mobile on EFL Learners' Reading Practices in Najran University. English Language Teaching,9(5), 8. https://doi.org/10.5539/elt.v9n5p8

[32] Alhinty, M. (2014). Young language learners' collaborative learning and social interaction as a motivational aspect of the iPad. 2014 International Conference on Interactive Mobile Communication Technologies and Learning (IMCL2014). https://doi.org/10.1109/IMCTL. 2014.7011106

[33] Chen, C., \& Wang, C. (2015). The Effects of Learning Style on Mobile AugmentedReality-Facilitated English Vocabulary Learning. 2015 2nd International Conference on Information Science and Security (ICISS). https://doi.org/10.1109/ICISSEC.2015.7371036

[34] Suwantarathip, O., \& Orawiwatnakul, W. (2015). Using mobile-assisted exercises to support students vocabulary skill development. The Turkish Online Journal of Educational Technology, 14(1), 163-171.

[35] Berns, A., Palomo-Duarte, M., Dodero, J. M., Ruiz-Ladrón, J., \& Márquez, A. C. (2015). Mobile apps to support and assess foreign language learning. Critical CALL-Proceedings of the 2015 EUROCALL Conference, Padova, Italy. https://doi.org/10.14705/ rpnet.2015.000309

[36] Hong, J., Hwang, M., Tai, K., \& Chen, Y. (2014). Using calibration to enhance students' self-confidence in English vocabulary learning relevant to their judgment of overconfidence and predicted by smartphone self-efficacy and English learning anxiety. Computers \& Education,72, 313-322. https://doi.org/10.1016/j.compedu.2013.11.011

[37] Rahimi, M., \& Soleymani, E. (2015). The Impact of Mobile Learning on Listening Anxiety and Listening Comprehension. English Language Teaching, 8(10). https://doi.org/10.5539/elt.v8n10p152

[38] Hsu, C., Hwang, G., \& Chang, C. (2013). A personalized recommendation-based mobile learning approach to improving the reading performance of EFL students. Computers \& Education, 63, 327-336. https://doi.org/10.1016/j.compedu.2012.12.004

[39] Davie, N., \& Hilber, T. (2015). Mobile-Assisted Language Learning: Student Attitudes to Using Smartphones to Learn English Vocabulary. International Association for Development of the Information Society.

[40] Sun, J. C. Y., Chang, C., Chen, M. J., \& Lin, Y. Y. (2016). Effects of enhanced elementmanaged instruction integrated with tablet PC-based collaborative polling on fifth graders' sight-word reading performance. International Journal of Mobile Learning and Organisation, 10(1-2), 102-116. https://doi.org/10.1504/IJMLO.2016.076192

[41] Lan, Y. J., \& Lin, Y. T. (2016). Mobile Seamless Technology Enhanced CSL Oral Communication. Educational Technology \& Society, 19 (3), 335-350. 
[42] Sandberg, J., Maris, M., \& Geus, K. D. (2011). Mobile English learning: An evidencebased study with fifth graders. Computers \& Education,57(1), 1334-1347. https://doi.org/10.1016/j.compedu.2011.01.015

[43] Albadry, H. (2015). The effect of iPad assisted language learning on developing EFL students' autonomous language learning. Critical CALL - Proceedings of the 2015 EUROCALL Conference, Padova, Italy. https://doi.org/10.14705/rpnet.2015.000302

[44] Wong, L.-H., Hsu, C.-K., Sun, J., \& Boticki, I. (2013). How Flexible Grouping Affects the Collaborative Patterns in a Mobile- Assisted Chinese Character Learning Game? Educational Technology \& Society, 16 (2), 174-187.

\section{Authors}

Veronica Persson has a master in Computer and Systems sciences from the department of Computer and system sciences, Stockholm University.

Jalal Nouri is an associate professor at the department of Computer and system sciences, Stockholm University.

Article submitted 11 December 2017. Resubmitted 23 January 2018. Final acceptance 06 February 2018. Final version published as submitted by the authors. 